NASA Technical Memorandum 101976

AIAA-89-1059

\title{
Comparison of Propeller Cruise Noise Data Taken in the NASA Lewis 8- by 6-Foot Wind Tunnel With Other Tunnel and Flight Data
}

(NASA-TA-101976) CCBEAEISCA CE EECFELLEB CECISE RCISE TAIA TAKE IB IEL NASA LESIS 8FIJGET CATA (UASA) Ż TE CIHE TOENEL AND CSCL 20A

\author{
$\$ 89-2,1628$ \\ Unclas \\ $63 / 710199104$
}

James H. Dittmar

Lewis Research Center

Cleveland, Ohio

Prepared for the

12th Aeroacoustics Conference

sponsored by the American Institute of Aeronautics and Astronautics

San Antonio, Texas, April 10-12, 1989 


\title{
COMPARISON OF PROPELLER CRUISE NOISE DATA TAKEN IN THE NASA LEWIS

\author{
8- BY 6-FOOT WIND TUNNEL WITH OTHER TUNNEL AND FLIGHT DATA
}

\author{
James Dittmar \\ National Aeronautics and Space Administration \\ Lewis Research Center \\ Cleveland, Ohio 44135
}

\begin{abstract}
SUMMARY
The noise of advanced high speed propeller models measured in the NASA Lewis 8 - by 6-Foot Wind Tunnel has been compared with model propeller noise measured in another tunnel and with full-scale propeller noise measured in flight. Good agreement was obtained for the noise of a model counterrotation propeller tested in the 8- by 6-Foot Wind Tunnel and in the acoustically treated test section of the Boeing Transonic Wind Tunnel. This good agreement indicates the relative validity of taking cruise noise data on a plate in the 8- by 6-Foot wind Tunnel compared with the free-field method in the Boeing tunnel. Good agreement was also obtained for both single rotation and counterrotation model noise comparisons with full-scale propeller noise in flight. The good scale model to full-scale comparisons indicate both the validity of the 8- by 6-Foot Wind Tunnel data and the ability to scale to full size. Boundary layer refraction on the plate provides a limitation to the measurement of forward arc noise in the 8-by 6-Foot wind Tunnel at the higher harmonics of the blade passing tone. The use of a validated boundary layer refraction model to adjust the data could remove this limitation.
\end{abstract}

\section{INTRODUCTION}

The noise of advanced design high speed propeller models has been measured at cruise conditions in the NASA Lewis 8- by 6-Foot Wind Tunnel. Some of the more recent data for both single- and counterrotation models can be found in references 1 through 3 . The NASA Lewis 8 - by 6 -Foot Wind tunnel is not acoustically treated and the data taken here is subject to continual scrutiny to assess its validity. Previous comparisons of the single-rotation propeller data with data taken on a model propeller in flight were presented in reference 4. Good agreement was shown between the 8- by 6-Foot Wind Tunnel data and the boom data on the airplane.

The present paper expands the comparison of the NASA 8- by 6-Foot wind Tunnel data with additional data beyond that reported in reference 4 . The noise of a model counterrotation propeller measured in the 8- by 6-Foot Wind Tunnel and in the acoustically treated test section of the Boeing Transonic Wind Tunnel is compared herein for validation of model size data. Data from the 8 - by 6-Foot wind Tunnel on the same counterrotation propeller model are compared with data from a full size counterrotation propeller installed on a Boeing 727 airplane. The full size propeller data were obtained by the NASA Learjet airplane flying in formation with the Boeing 727 airplane. Single

Copyright (C) 1989 by the American Institute of Aeronautics and Astronautics, Inc. No copyright is asserted in the

United States under Title 17, U.S. Code. The U.S. Government has a royalty-free license to exercise all rights under the copyright claimed herein for Governmental purposes.

All other rights are reserved by the copyright owner. 
rotation propeller model data taken in the 8- by 6-Foot Wind Tunnel were compared with data from the Large-scale Advanced Propeller (LAP) flown on the Propfan Test Assessment Airplane (PTA). Cruise noise data were obtained on the PTA airplane by microphones on the airplane fuselage and on a boom located outboard of the propeller. The model to full size comparisons, single and counterrotation, are done to assess both the validity of the 8- by 6-Foot Wind Tunnel data and the ability to scale that data.

\section{APPARATUS AND PROCEDURE}

Noise data taken on scale model propellers in the NASA Lewis 8- by 6-Foot Wind Tunnel are compared with other tunnel and flight data. The description and testing methods for obtaining these data are as follows:

\section{NASA Lewis 8 - by 6-Foot Wind Tunnel}

Noise data were taken on single- and counterrotation propeller models in the NASA Lewis 8- by 6-Foot Wind Tunnel using pressure transducers embedded in a plate suspended from the tunnel ceiling (refs. 1 to 3 ). Figure 1 shows a photograph and sketches of the installation for the single-rotation propeller testing and figure 2 shows the counterrotation installation. Data were taken with the plate located 3-tenths of a propeller diameter above the propeller tip.

The use of the plate enables the transducers to be placed close to the propeller while blocking the possible reflections from the wall behind the plate. The direct noise path from the propeller to the transducers is therefore much shorter than any of the possible reflection paths from the other walls of the tunnel. The combination of this path length advantage and the downstream convection beyond the plate of the reflections from the high noise region of the propeller (ref. 5) enables the direct acoustic signal to be measured on the plate. The advantage of the plate method is that advanced high speed propeller noise can be measured without the expense and complication of installing acoustic treatment in the test section. The plate method does have a limitation with respect to testing in an anechoic test section because of the boundary layer on the plate. The boundary layer refracts some of the propeller noise away from the measurement transducers. The amount of the refraction depends on the ratio of sound wavelength to boundary layer thickness and is more severe the farther forward of the propeller the transducer is located (ref. 6). The comparisons to be made in this paper will indicate the importance of this boundary layer refraction limitation.

Boundary layer refraction is also a factor in attempting to design acoustic treatment to operate at high Mach numbers upstream of a propeller source as was done in reference 7 . Likewise, boundary layer refraction must be accounted for in interpreting fuselage measurements upstream of a propeller in flight.

The data taken by the pressure transducers on the plate are spectrally analyzed to determine the propeller blade passing tones and their harmonics. It is this tone data that is used in the comparison with the data taken elsewhere. 
Boeing Transonic Wind Tunnel

Model counterrotation propellers were tested for acoustics in the acoustically treated test section of the Boeing Transonic Wind Tunnel. Figure 3 shows side and rear view sketches of the test section. The acoustically treated test section is $2.44 \mathrm{~m}(8 \mathrm{ft})$ high by $3.66 \mathrm{~m}(12 \mathrm{ft})$ wide by $4.42 \mathrm{~m}$ $(14.5 \mathrm{ft})$ long and has $61 \mathrm{~cm}(2 \mathrm{ft})$ corner fillets. The acoustic walls are $30.5 \mathrm{~cm}$ (12 in.) thick foam covered by perforated metal and were designed to be anechoic from 300 to $8000 \mathrm{~Hz}$. A more complete description of the tunnel acoustic design can be found in reference 7 .

The acoustic data were taken by two microphones mounted on a sting supported from the ceiling. The free-field microphones were located on two sidelines $67 \mathrm{~cm}(2.2 \mathrm{ft})$ and $134 \mathrm{~cm}(4.4 \mathrm{ft})$ from the propeller test rig centerline. The propeller noise directivities were obtained by traversing the microphone sting fore and aft in the wind tunnel.

Full-Scale Counterrotation Propeller on Boeing 727

Measured by NASA Learjet Airplane

A full-scale counterrotation demonstrator engine was installed on a Boeing 727 aircraft as shown in figure 4. The propeller was nominally $3.57 \mathrm{~m}$ $(11.7 \mathrm{ft})$ in diameter. The aircraft was flown at a cruise altitude of $9906 \mathrm{~m}$ (32 $500 \mathrm{ft}$ ) and at a cruise Mach number of 0.72 with the propeller operating at cruise power settings. Acoustic data were obtained from a Learjet chase plane which was instrumented with nose and wing tip microphones.

The Learjet flew in formation with the Boeing 727 at various sideline angles from the counterrotation propeller as shown in figure 5 . A more detailed description of this test and some initial wind tunnel to flight comparisons can be found in reference 8 .

\section{Propfan Test Assessment Airplane}

The Large-scale Advanced Propeller (ref. 9), $2.74 \mathrm{~m}$ ( $9 \mathrm{ft}$ ) in diameter, was flow on a testbed Gulfstream II aircraft as part of the Propfan Test Assessment Program (PTA)(ref. 10). A photograph of the airplane with the propeller installed on the left wing is shown in figure 6 . For the data discussed in this report, the airplane was operated at cruise altitude and Mach number with the propeller operating at cruise thrust conditions. Noise data were obtained by microphones embedded flush in the airplane fuselage and microphones on the boom shown close outboard of the propeller. Initial results from this testing can be found in reference 11 .

\section{RESULTS AND DISCUSSION}

In order to compare the various data sets, it is first necessary to adjust the data to the same conditions. In each case, the data taken in the 8- by 6-Foot Wind Tunnel were adjusted to the conditions of the other tests. The description of each of these adjustments is included in the following comparison sections. 


\section{Comparison with Boeing Transonic Wind Tunnel Data}

Data taken on a scale model counterrotation propeller, F7-A7, in the NASA Lewis 8- by 6-Foot Wind Tunnel were compared with data on the same propeller taken in the acoustically treated test section of the Boeing transonic wind tunnel. In both tunnels, the propellers were run with eight blades in each propeller and at approximately equal front and rear rotational speeds which were 100 percent of design speed. The blade passing tones from each propeller then occur at the same frequency and the interaction tones occur at the same frequencies as the harmonics. Therefore, the spectrum only shows individual tones at each harmonic which are the summation of the two propeller harmonics and the interaction tones. In both tunnels the axial Mach number was 0.72 and the propellers had the same blade setting angles of $56.9^{\circ}$ on the front propeller and $54.5^{\circ}$ on the aft propeller.

The 8 - by 6 -Foot wind Tunnel data were adjusted to the Boeing conditions using standard adjustments. The measurements were taken at two different distances. An adjustment of 20 times the $\log$ of the distance ratio (distances measured from rig centerline) was applied to the 8- by 6-Foot Wind Tunnel data. The $20 \mathrm{log}$ of the distance ratio was found to apply for different plate to propeller distances in the 8 - by 6-Foot Wind Tunnel and is used in this report for all distance corrections. The 8- by 6-Foot Wind Tunnel data were thus reduced by $2.5 \mathrm{~dB}$ to adjust them to the Boeing distance. Table I indicates the conditions in the two tunnels and the adjustments used. The two tunnels operated at different atmospheric conditions. Twenty times the log of the ratio of the tunnel pressures was used for this adjustment which results in the 8- by 6-Foot Wind Tunnel data being further reduced by $1.3 \mathrm{~dB}$ (8- by 6 -Foot Wind Tunnel at $83.4 \times 10^{3} \mathrm{~N} / \mathrm{m}^{2}(12.2 \mathrm{psi})$, Boeing Tunnel at $71.8 \times 10^{3} \mathrm{~N} / \mathrm{m}^{2}$ ( $10.5 \mathrm{psi}$ ). The data taken in the 8 - by 6 -Foot Wind Tunnel were taken on a flat surface where a pressure amplification of $6 \mathrm{~dB}$ is assumed. Since the Boeing data is taken with a free field microphone another $6 \mathrm{~dB}$ is taken from the 8- by 6-Foot Wind Tunnel data. The 8- by 6-Foot Wind Tunnel data are thus reduced by a total of $9.8 \mathrm{~dB}$ to compare them with the Boeing tunnel data. $A$ small adjustment in sideline angle was also applied to the 8-by 6-Foot Wind Tunnel data since these angles were measured from a point halfway between the two propellers while the Boeing angles were measured from the pitch change axis of the rear propeller. No adjustments were made for the recognized boundary layer refraction on the plate in the 8 - by 6-Foot Wind Tunnel and the comparisons are intended to show the importance of refraction.

When the above adjustments were applied to the 8- by 6-Foot Wind Tunnel data they were plotted on the traverse microphone data plots from the Boeing tunnel. These comparisons are shown in figure 7 for the first five harmonics. The agreement at the blade passing tone and twice blade passing tone, figures $7(a)$ and $7(b)$, is very good. At the higher harmonics, 3, 4, and 5 times blade passing frequency, figures $7(c)$ through $7(e)$, the data from the two tunnels agree well behind the plane of rotation but the 8-by 6-Foot wind Tunnel data are lower in front of the plane of rotation. The 8-by 6-Foot Wind Tunnel data are lower toward the front as the result of refraction from the boundary layer on the acoustic plate in the 8 - by 6 -Foot Wind Tunnel. Very little refraction is present at the blade passing frequency and the 2 nd 
harmonic but as the frequency is increased, the higher harmonic wavelengths of the sound become smaller and more refraction from the plate boundary layer is present.

The refraction does present a limitation on the use of the 8 - by 6-foot Wind Tunnel. The boundary layer refraction at the higher harmonics at the forward angles can bring the tone level down below the tunnel background level such that the tone cannot be measured using time averaged spectra. This provides a limitation on the 8- by 6-Foot Wind Tunnel for obtaining the higher harmonics at the forward angles.

The agreement between the 8-by 6-Foot wind Tunnel data and the Boeing acoustic wind tunnel data is very good at the blade passing tone and at twice blade passing tone. The comparison behind the plane of rotation is good at the higher harmonics but the boundary layer refraction on the plate in the 8 - by 6-Foot Wind Tunnel places a limitation for the forward angles at the higher harmonics. The favorable comparisons show the relative validity of obtaining cruise noise acoustic data using the plate in the 8- by 6-Foot Wind Tunnel with the free-field method of obtaining data in the acoustically treated test section of the Boeing transonic wind tunnel.

\section{Comparison with a Full-Scale Counterrotation Propeller}

Data taken on a scale model counterrotation propeller, F7-A7, in the NASA Lewis 8-by 6-Foot Wind Tunnel were compared with data taken on a full-scale version of this propeller in flight. The full-scale propeller was flown on a Boeing 727 airplane ( $f i g .4$ ). The noise was measured by a microphone on the wing tip tank of the NASA Lewis Learjet airplane which flew in formation with the Boeing 727 ( $f i g .5$ ). These flight noise data were presented in reference 8 and some preliminary airplane to tunnel comparisons for the propeller blade passing tone were included.

During the 8 - by 6 -Foot wind Tunnel tests the nominal design cruise condition was an axial Mach number of 0.72 and the blade angles set at $58.5^{\circ}$ for the front and $55.7^{\circ}$ for the aft blade. The flight tests were performed later at various blade setting angles. The propeller blade angles were automatically controlled in the flight test to give equal fore and aft propeller torques. As indicated in reference 8 , some installation effect resulted in an unexpected difference between front and rear blade angles. The condition closest to the tunnel design cruise, where good acoustic data were obtained, was flight 5.9 of reference 8 . Here the airplane was flown at an axial Mach number of 0.72 at an altitude of $9906 \mathrm{~m}(32500 \mathrm{ft})$. The blade angles were $59.3^{\circ}$ on the front and $52.9^{\circ}$ on the aft. The flight 5.9, propeller power was only about 75 percent of design corresponding to a power coefficient (based on annulus area) of 3.14 compared to a power coefficient of 4.21 in the tunnel.

The blade setting angles differed between the tunnel and flight by $0.8^{\circ}$ on the front propeller and $2.8^{\circ}$ on the aft. The front propeller blade setting angles were close enough that the front propellers, scale and full-size, were probably producing similar thrust and power coefficients so that the front propeller noise may be compared. The rear propeller blade setting angles in flight are significantly lower than on the model in the tunnel. The noise for the aft propeller in flight would then not be expected to compare well with 
the model data. In summary, even though the propeller conditions are not identical between the model full-scale, a comparison of the noise data is still worthwhile to investigate the scaling question.

To convert from the scale model wind tunnel data to full-size, the noise in decibels is assumed to vary with $10 \mathrm{log}$ of the thrust with the thrust in turn varying as the square of the propeller diameter. The thrust is scaled on propeller diameter squared since no direct measurement of full scale propeller thrust is made in flight. The thrust adjustment adds 15.2 decibels to the 8- by 6-Foot Wind Tunnel data to adjust to full-size. This thrust adjustment converts the 8 - by 6-Foot Wind Tunnel data for a propeller with $58.5^{\circ}$ front and $55.7^{\circ}$ aft blade angles to a full-size propeller with the same angles. Table II contains the test conditions and the corrections applied.

The 8 - by 6 -Foot Wind Tunnel data are adjusted by $20 \log$ of the distance ratio to convert to full size. The distance correction reduces the $8-$ by 6 -Foot Wind Tunnel data by $39.6 \mathrm{~dB}$.

The airplane was flown at $9906 \mathrm{~m}$ (32 $500 \mathrm{ft}$ ) with a standard atmospheric pressure of $27.1 \times 10^{3} \mathrm{~N} / \mathrm{m}^{2}(3.96 \mathrm{psi})$ and the tunnel was operated with a tunnel pressure of $83.4 \times 10^{3} \mathrm{~N} / \mathrm{m}^{2}(12.2 \mathrm{psi})$. The adjustment for atmospheric conditions was taken as $20 \mathrm{log}$ of the pressure ratio which gave the result that the 8 - by 6 -Foot Wind Tunnel data should be reduced by $9.8 \mathrm{~dB}$ to convert to full scale conditions.

The data in the 8- by 6-Foot Wind Tunnel were taken on a flat plate and $6 \mathrm{~dB}$ are assumed as pressure doubling on this plate. In flight the noise levels were measured on the cylindrical wing tip tank of the Learjet airplane. This tip tank is approximately $30.5 \mathrm{~cm}(1 \mathrm{ft})$ in diameter. The diffraction around this cylinder, as indicated by reference 12 , yields a level $5 \mathrm{~dB}$ above free field at the blade passing frequency of the full scale propeller, and $5.5 \mathrm{~dB}$ at twice blade passing frequency.

The 8 - by 6-Foot wind Tunnel data are then reduced by a total of $35.2 \mathrm{~dB}$ at the blade passing tone and 34.7 decibels at twice blade passing tone to compare with the full scale data measured on the Learjet tip tank. Good higher harmonic data were not available on the airplane so only the first two harmonics are compared.

As indicated in the previous model comparison section, little boundary layer refraction was observed for the tones at the blade passing frequency and twice blade passing frequency in the 8-by 6-Foot wind Tunnel testing at $M=$ 0.72 . The boundary layer refraction on the Learjet tip tank is also expected to be negligible at these two tones for the angles measured. Therefore, no boundary layer refraction corrections were applied here. Also, no adjustments have been made for installation effects on the airplane. As can be seen in figure 4, the pylon supporting the engine is directly in front of the propeller. The aerodynamic interaction of this pylon with the propeller would be an additional noise source in flight that does not exist in the tunnel. However, it is felt that the interaction noise is less than the propeller alone noise, at cruise, so no correction was made. 
The first comparisons are made using a narrowband analys is with a bandwidth wide enough that the separate front and rear propeller tones are included in the same band. These spectra have one tone at the blade passing frequency, one tone at twice blade passing frequency, etc.

When the above adjustments were applied to the 8 - by 6-Foot Wind Tunnel model data to convert to full scale, the comparison of figure 8 resulted. The first two tones are plotted in parts a and b, respectively. As can be observed the adjusted model data and the full scale data compare fairly well in shape. Good comparison is shown for the data around $115^{\circ}$ for both harmonics but around $90^{\circ}$ and farther forward the wind tunnel data is above the airplane data. This may be the result of the wind tunnel data being taken at a higher power coefficient. The good comparison around $115^{\circ}$ indicates that the adjustments to full scale are at least approximately correct.

To further explore the comparison between wind tunnel and flight the data were analyzed with a narrower bandwidth. In both cases the propellers had eight blades in both rows but the two rows were operated at differences in speed of 40 to $60 \mathrm{rpm}$. With a sufficiently narrow bandwidth, the separate front and rear propeller tones were determined.

As indicated in reference 8 , there was some question as to which was the front and which the aft blade passing tone on the airplane. The two tones are only distinguishable based on their frequency. The faster rotating blade row has the higher frequency since the number of blades in each row are the same. The data on the airplane were questioned because the tone noise of the indicated aft propeller was peaking farther forward than the tone noise from the propeller being identified as the front propeller. The wind tunnel data, such as that from reference 2, clearly indicate the front propeller noise peaks forward of the aft propeller noise. Based on this and a preliminary comparison of the F7-A7 airplane and tunnel data which showed that the supposedly aft propeller full scale noise compared better with the forward model noise, and vice versa, the indicated propeller signals are assumed to have been reversed during the airplane test.

With the above assumption, the individual blade passing tones are compared in figure 9. As can be observed the forward propeller tones compare very well particularly at $90^{\circ}$ and $115^{\circ}$. The noise comparison at the $60^{\circ}$ position still shows the tunnel data being a little high. The aft blade passing tone does not compare as well as the front tone with both the $60^{\circ}$ and $90^{\circ}$ positions having the tunnel data a little high. This is quite probably the result of the full scale aft propeller not being as highly loaded as the aft propeller was in the wind tunnel test. The tones at twice blade passing frequency are shown in figure 10. Again the forward blade noise comparisons are very good while the aft blade noise comparison is not as good.

The fair comparison between the overall tone level for tunnel model and full size flight data, even though the propellers were not tested at exactly the same blade setting angles, indicates that the scaling parameters used are probably correct. The good comparison of the forward propeller tones, where the blade angles were almost the same, more strongly shows that the scaling is correct and further indicates the validity of obtaining noise data in the 8- by 6-Foot Wind Tunnel. In other words it appears that valid scale model counterrotation noise data at cruise conditions can be obtained in the 8 - by 6 -Foot Wind Tunnel and also that the data can be projected to full scale flight conditions. 


\section{Comparison with a Full-Scale Single-Rotation Propeller}

Data taken on a scale model single-rotation propeller, SR-7A, in the NASA Lewis 8- by 6-Foot Wind Tunnel were compared with data taken on a full-scale version of this propeller in flight. The full scale propeller was flown on the PTA airplane, a modified Gulfstream II and the noise was measured by microphones embedded in the airplane fuselage and on a boom located outboard of the propeller (fig. 6). A description of this flight test and some of the airplane data are found in reference 11.

During the 8 - by 6 -Foot Wind Tunnel tests the propeller was tested at its nominal design condition at an axial Mach number of 0.8 . The flight condition was for the equivalent design point cruise power at a Mach number of $0.8,10$ $670 \mathrm{~m}$ (35000 ft) altitude. The engine nacelle was tilted downward at a $-1^{\circ}$ angle to provide the conditions closest to axial inflow to the propeller.

To convert from the scale model wind tunnel data to full size, the noise was adjusted by $10 \mathrm{log}$ of thrust in the same manner as the counterrotation data. The thrust adjustment adds $12.8 \mathrm{~dB}$ to the 8 - by 6 -Foot Wind Tunnel data (table III). The distance adjustment, based on $20 \mathrm{log}$ of distance ratio, reduces the wind tunnel data by $15.8 \mathrm{~dB}$.

The airplane was flown at $10670 \mathrm{~m}$ (35 $000 \mathrm{ft}$ ) and the tunnel was operated at $78.6 \times 10^{3} \mathrm{~N} / \mathrm{m}^{2}(11.5 \mathrm{psi})$ for these tests only one period. The adjustment for atmospheric conditions, $20 \mathrm{log}$ of the pressure ratio, gave the result that the 8 - by 6 -Foot Wind Tunnel data should be reduced by $10.5 \mathrm{~dB}$. The total reduction from wind tunnel to flight was then $13.5 \mathrm{~dB}$.

The comparisons made here are without any corrections for boundary layer refraction even though it will be present on both the acoustic plate in the wind tunnel and on the airplane fuselage. The data comparisons will give an indication of the difference between the fuslage and plate boundary layer refractions. The airplane fuselage data is from a row of microphones designated in reference 11 as "closest approach." Data from the boom microphones on the airplane are also compared.

The boom microphones were adjusted to the fuselage condition using the diffraction indicated from reference 12. The boom tapers from approximately $15.8 \mathrm{~cm}(6-1 / 4 \mathrm{in.})$ diameter at the transducer closest to the wing to $4.1 \mathrm{~cm}$ ( $1-5 / 8$ in.) diameter at the farthest forward transducer. The pressure amplifications from reference 12 for the boom transducers going from forward to aft are $0,0.5,0.5,1.0$, and $1.5 \mathrm{~dB}$ for the blade passing tone; $0.5,1.51 .5,2$, and 2.5 for $2 \mathrm{BPF} ; 1.0,2.0,2.5,3.5$, and 4.0 for $3 \mathrm{BPF} ; 1.5,3.0,3.5,4.0$, and 4.5 for $4 B P F$; and $1.5,4.0,4.0,4.5$, and 5.0 for $5 B P F$. The fuselage and plate are assumed to have $6 \mathrm{~dB}$ pressure amplification so the differences between the $6 \mathrm{~dB}$ and the above boom amplifications are added to the measured boom tones to put the data on the same basis.

Figure 11 shows the airplane fuselage, airplane boom and the scaled 8 - by 6-Foot wind Tunnel model data. The blade passing tone data is shown in figure $11(a)$. The 8 - by 6-Foot wind Tunnel data have scaled very well to full size with both the level and directivity shape being very close to that measured in flight. As can be seen in figure $11(\mathrm{a})$ the airplane boom data is 
somewhat higher than the airplane fuselage data with the 8 - by 6-foot Wind Tunnel data generally in between but somewhat closer to the boom levels. The difference between the boom and fuselage data is a possible indication of some installation effects on the propeller noise in-flight. The effect of the noise on one side being higher than on the other can be caused by the propeller being at an angle of attack to the flow as was shown previously for advanced propellers in references 13 and 14. The noise levels of the three data sets come together at the forward angles and show little or no effect of boundary layer refraction at the blade passing tone, either in the 8- by 6-Foot Wind Tunnel to fuselage comparison or in the boom to fuselage comparison. The good comparison of the 8 - by 6-Foot wind Tunnel data with the flight data at the blade passing tone indicates the validity of the 8-by 6-Foot Wind Tunnel data and that the scaling is correct.

The comparison at twice blade passing frequency is shown in figure $11(b)$. Here a larger difference exists between the airplane boom and fuselage data indicating that the installation effect is being more strongly felt by the second harmonic. The 8- by 6-Foot Wind Tunnel data peak is between the two sets of airplane data but here the effect of boundary layer refraction on the plate in the 8 - by 6-Foot Wind Tunnel is clearly seen. The 8- by 6-Foot Wind Tunnel data to the front is much below the airplane data and was not measurable above the tunnel background noise at points farther forward than the 0.2 diameter position. The high background noise level combined with the boundary layer refraction on the plate places a limitation on the ability to measure the forward radiated noise in the 8 - by 6 -Foot Wind Tunnel. The fuselage data are not showing any boundary layer refraction relative to the boom.

The comparison at three times blade passing tone is shown in figure $11(c)$. Here the boom and fuselage peaks are even farther apart in level and the boundary layer effect on the 8- by 6-Foot Wind Tunnel data is clearly indicated. In addition, the 8- by 6-Foot Wind Tunnel data are exhibiting strange behavior behind the plane of rotation, first showing a peak, then a valley and then rising toward another peak. The peak and valley behavior is very similar to a ground reflection pattern. The peak and valley pattern has not been observed in any of the counterrotation data at this or any other frequency, (see refs. 2 and 3 , or see fig. $7(\mathrm{c})$ of this paper for examples) or in any of the single rotation data taken with transducers on the ceiling of the wind tunnel (refs. 4, 15, and 16). This behavior was also not seen for the SR-7A propeller data taken with ceiling transducers (ref. 17). Because the pattern has not been seen in any of the other 8 - by 6-Foot Wind Tunnel measurements, it does not appear to be a tunnel reflection. This pattern, if it is a reflection, is only seen here with the plate close to the single rotation test rig and the most likely cause is a reflection from the drive rig. The peak and valley pattern is not in the counterrotation data with the plate close to the counterrotation test rig and in some way seems to be tied to the single rotation test rig. As can be seen in figures 1 and 2 , parts (c), the single rotation and counterrotation test rigs have different shapes behind the propeller plane of rotation. The counterrotation rig continues to neck down to smaller diameters and does not increase in diameter until beyond the end of the transducer positions on the acoustic plate. The single rotation rig however first increases in diameter behind the propeller and then decreases in diameter. The shape of the counterrotation rig would tend to reflect noise farther downstream behind 
the acoustic plate, while the shape of the single rotation rig may tend to reflect noise somewhat upstream and onto the plate. It may be that at this frequency, 3BPF, the single rotation rig is reflecting noise back onto the plate and causing the behavior noted in figure $11(\mathrm{c})$.

The noise comparisons at 4BPF and 5BPF are shown in figures 11 (d) and 11(e). In general, these figures show similar comparisons as that for $2 B P F$ with the boom data above the fuselage data and the 8- by 6-Foot Wind Tunne 1 data showing boundary layer refraction toward the front.

The comparison between the scaled 8- by 6-Foot Wind Tunnel data and the full scale propeller data is very good at the blade passing frequency. As a result of boundary layer refraction, the data comparison at the higher harmonics is not as good. An anomaly also exists for the tone at 3BPF aft of the propeller which may be a reflection from the single rotation drive rig. In general, the good comparison indicates the validity of the 8- by 6-Foot Wind Tunnel noise measurements and shows the ability to scale the data to fullsize. The combination of high tunnel background noise and boundary layer refraction on the acoustic plate in the 8- by 6-Foot Wind Tunnel does present a limitation to the measurement of forward arc noise at the higher harmonics.

\section{CONCLUDING REMARKS}

The noise of advanced design high speed propeller models measured in the NASA Lewis 8 - by 6-Foot Wind Tunnel has been compared with propeller noise measured in another tunnel and full-scale flight tests. The 8- by 6-Foot Wind Tunnel model data for a counterrotation propeller operating at 0.72 Mach number cruise conditions agreed very well with model data taken on the same propeller at the same conditions in the acoustically treated test section of the Boeing transonic wind tunnel. This good agreement indicated the relative validity of taking cruise noise data on a plate in the 8- by 6-Foot Wind Tunnel compared with the free-field method in the Boeing tunnel. Boundary layer refraction was observed at the third and higher propeller harmonics for the 8- by 6-Foot Wind Tunnel data taken on the acoustic plate. This boundary layer refraction presents a limitation on the ability to take data at the higher harmonics in front of the propeller.

Comparisons of 8 - by 6-Foot Wind Tunnel model counterrotation data at $M=0.72$ cruise conditions with full-scale propeller data in flight showed good agreement even though the propellers were not exactly at the same blade setting angles. The good agreement indicated not only the validity of the 8 - by 6-Foot Wind Tunnel data but also the ability to scale the 8- by 6-Foot Wind Tunnel data to full size.

The 8 - by 6-Foot wind Tunnel data for a single rotation propeller at $M=0.8$ cruise conditions were compared with full scale data taken in flight on the PTA airplane. Both fuselage and boom data were obtained on the airplane and in general the scaled 8- by 6-Foot Wind Tunnel data fell partway between the boom and fuselage data. This further indicated both the validity of the 8- by 6-Foot Wind Tunnel data and the ability to scale to full size. Some indication of a drive rig noise reflection was observed at the third harmonic and boundary layer refraction effects were seen at the second and higher harmonics. 
In summary, the good agreement of the model to model noise comparisons for a counterrotation propeller have indicated the validity of taking propeller cruise noise measurements in the 8 - by 6-Foot Wind Tunnel. The good agreement of both single rotation and counterrotation model data with fullscale propeller data in flight have indicated both the validity of the 8- by 6-Foot Wind Tunnel data and the ability to scale to full size. Boundary layer refraction on the plate in the 8- by 6-Foot Wind Tunnel does provide a limitation to the measurement of forward arc noise at the higher harmonics of the blade passing frequency. The use of a validated boundary layer refraction model to adjust the data could remove this limitation.

\section{ACKNOWLEDGMENT}

The author wishes to thank Phil Gliebe of General Electric and Harold Bartel of Lockheed for permission to use data which has not been previously published.

\section{REFERENCES}

1. Dittmar, J.H., and Stang, D.B., "Cruise Noise of the 2/9th Scale Model of the Large-Scale Advanced Propfan (LAP) Propeller, SR-7A," NASA TM-100175, 1987.

2. Dittmar, J.H., and Stang, D.B., "Noise Reduction for Model Counterrotation Propeller at Cruise by Reducing Aft-Propeller Diameter," NASA TM-88936, 1987.

3. Dittmar, J.H., "The Effect of Front-to-Rear Propeller Spacing on the Interaction Noise of a Model Counterrotation Propeller at Cruise Conditions," NASA TM-100121, 1987.

4. Dittmar, J.H., "Further Comparison of Wind Tunnel and Airplane Acoustic Data for Advanced Design High Speed Propeller Models," NASA TM-86935, 1985.

5. Dittmar, J.H., Why Credible Propeller Noise Measurements are Possible in the Acoustically untreated NASA Lewis 8- by 6-Foot Wind Tunnel. Journal of the Acoustical Society of America, Vol. 75, No. 6, June 1984, pp. 1913-1914.

6. Dittmar, J.H.; Burns, R.J.; and Leciejewski, D.J.: An Experimental Investigation of the Effect of Boundary Layer Refraction on the Noise from a High-Speed Propeller. NASA TM-83764, 1984.

7. Bengelink, R.L., Doerzbacher, R.P., and Krynytzky, A.J., "The Development and Calibration of an Acoustic Wall Transonic Test Section," AIAA Paper 86-0759-CP, Mar. 1986.

8. Woodward, R.P., Loeffler, I.J., and Dittmar, J.H., "Measured Far-Field Flight Noise of a Counterrotation Turboprop at Cruise Conditions, "NASA TM-101383, 1989.

9. Sagerser, D.A., and Lundemann, S.G., "Large-Scale Advanced Propfan (LAP) Program Progress Report," AIAA Paper 85-1187, July 1985 (NASA TM- 87067). 
10. Withers, C., Bartel, H.W., Turnberg, J.E., and Braber, E.J., "Static Tests of the Propulsion System - Propfan Test Assessment Program," AIAA Paper $87-1728$, June 1987.

11. Poland, D.T., Bartel, H.W., and Brown, P.C., "PTA Flight Test Overview," AIAA Paper 88-2803, July 1988.

12. Wiener, F.M., "Sound Diffraction by Rigid Spheres and Circular Cylinders." Journal of the Acoustical Society of America, Vol. 19, No. 3, May 1947, pp. 444-451.

13. Dittmar, J.H., and Jeracki, R.J., "Noise of the SR-3 Propeller Model at $2^{\circ}$ and $4^{\circ}$ Angle of Attack," NASA TM-82738, 1981.

14. Woodward, R.P., "Measured Noise of a Scale Model High Speed Propeller at Simulated Takeoff/Approach Conditions," AIAA Paper 87-0526, 1987

(NASA TM-88920).

15. Dittmar, J.H., Jeracki, R.J., and Blaha, B.J., "Tone Noise of Three Supersonic Helical Tip Speed Propellers in a Wind Tunnel," NASA TM- 79167, 1979.

16. Dittmar, J H., and Jeracki, R.J., "Additional Noise Data on the SR-3 Propeller," NASA TM -81736, 1981.

17. Dittmar, J.H., "Preliminary Measurement of the Noise from the $2 / 9$ Scale Model of the Large-Scale Advanced Propfan (LAP) Propeller SR-7A," NASA TM$87116,1985$.

TABLE I. - ADJUSTMENTS OF NASA LEWIS 8- BY 6-FOOT WIND TUNNEL DATA TO BOEING TRANSONIC WIND TUNNEL CONDITIONS

[Propeller, F7/A7 model.]

(a) Test conditions

\begin{tabular}{|c|c|c|}
\hline & Boeing tunnel & 8 - by 6-Foot Wind Tunnel \\
\hline $\begin{array}{c}\text { B1ade setting angles } \\
\text { (front/rear), deg }\end{array}$ & $56.9 / 54.5$ & $56.9 / 54.5$ \\
$\begin{array}{c}\text { Propeller diameter, } \\
\text { cm (in.) }\end{array}$ & $62.3(24.5)$ & $62.3(24.5)$ \\
$\begin{array}{c}\text { Sideline distance, } \\
\text { cm (in.) }\end{array}$ & $67(26.4)$ & $49.8(19.6)$ \\
$\begin{array}{c}\text { Atmospheric kPa (psi) } \\
\text { pressure, kPa }\end{array}$ & $71.8(10.5)$ & $83.4(12.2)$ \\
\hline
\end{tabular}

(b) Amount of adjustment applied to tunnel data to convert to Boeing tunnel conditions, decibels

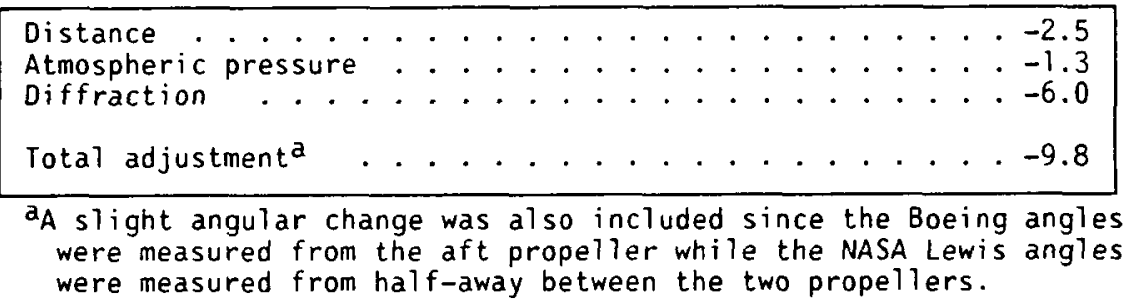


TABLE II. - ADJUSTMENTS OF NASA LEWIS 8- BY 6-FO0T WIND TUNNEL DATA TO FULL-SCALE PROPELLER NOISE CONDITIONS ON LEARJET AIRPLANE

(a) Test conditions

\begin{tabular}{|l|r|c|}
\hline & Learjet & 8- by 6-Foot Wind Tunnel \\
\hline $\begin{array}{c}\text { Propeller } \\
\text { (front/rear), deg }\end{array}$ & F7/A7 fullsize & F7/A7 model \\
$\begin{array}{l}\text { Propeller diameter, } \\
\text { cm (in.) }\end{array}$ & $357(140.4)$ & $58.5 / 55.7$ \\
$\begin{array}{l}\text { Sideline } \\
\text { distance, cm (in.) } \\
\text { Atmospheric } \\
\text { pressure, kPa(psi) }\end{array}$ & $\mathrm{a}_{47.2(155)}$ & $62.3(24.5)$ \\
\hline
\end{tabular}

$a_{\text {In meters }(f t)}$.

(b) Amount of adjustment applied to NASA Lewis tunnel data to convert to Learjet condition, decibels

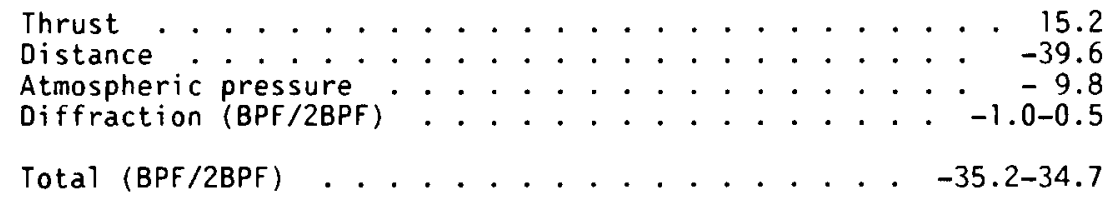

TABLE III. - ADJUSTMENT OF NASA LEWIS 8- BY 6-FOOT WIND TUNNEL DATA TO PROPFAN TEST ASSESSMENT AIRPLANE (PTA) CONOITIONS

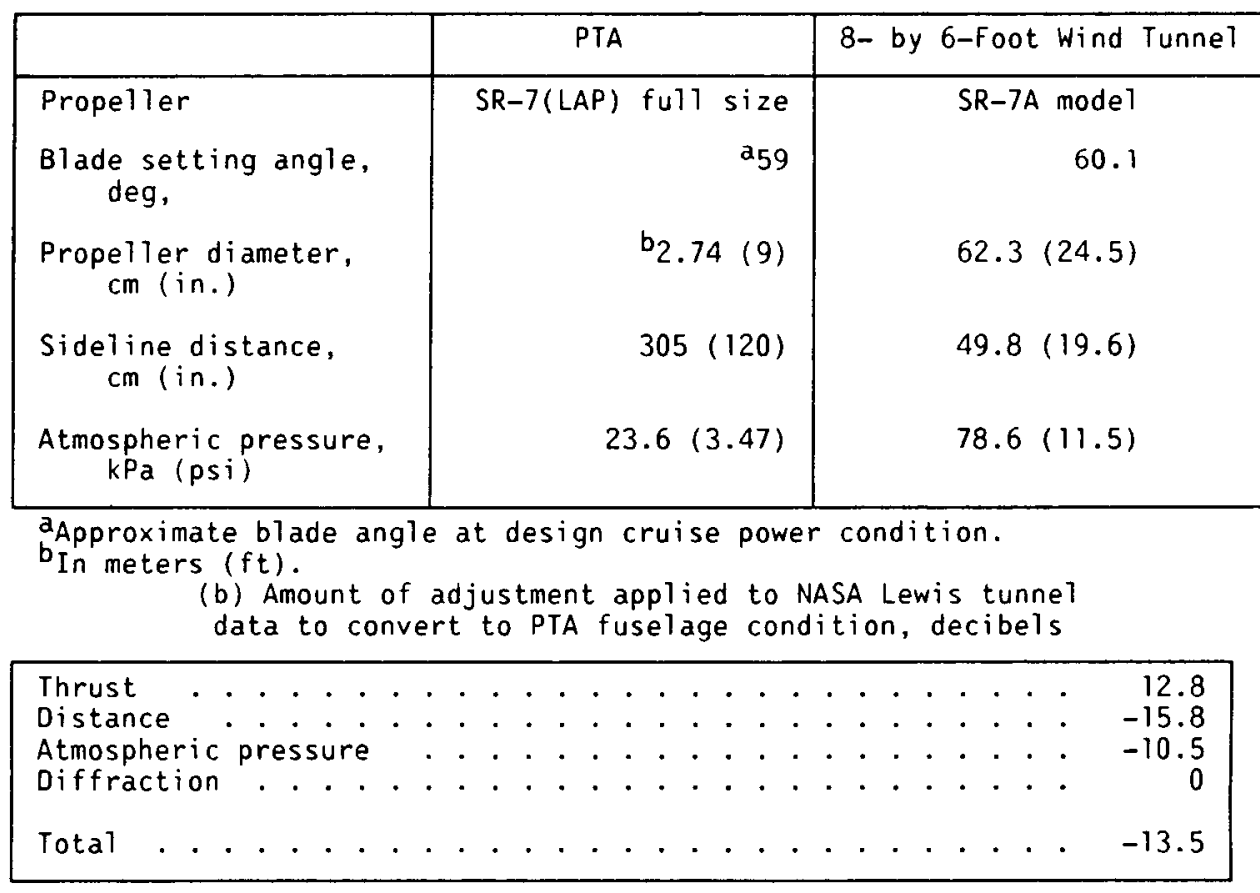




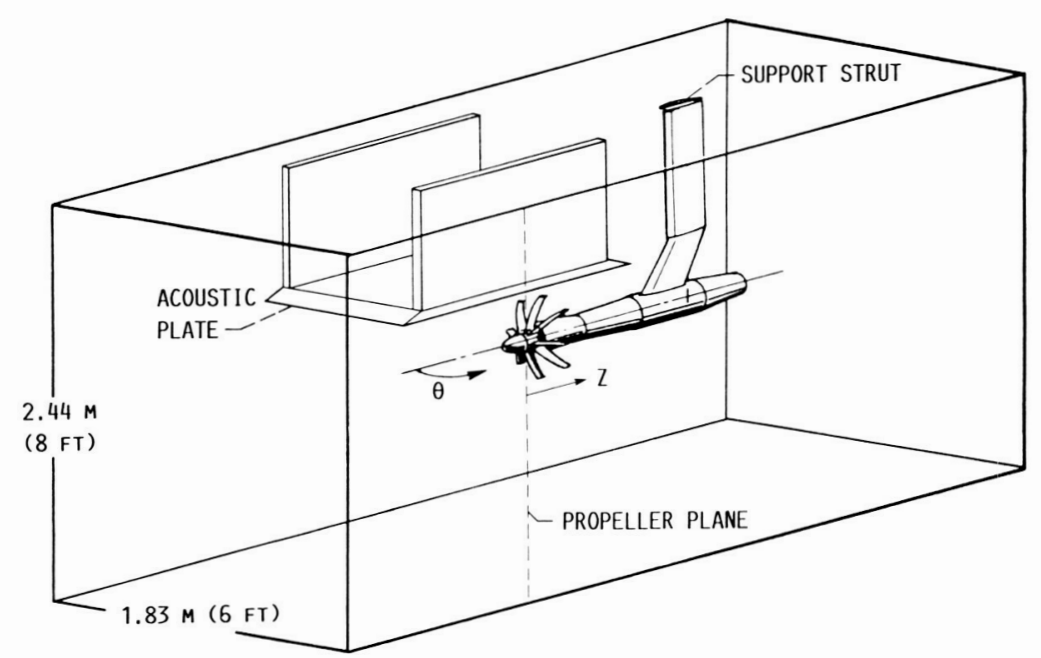

(a) PERSPECTIVE.

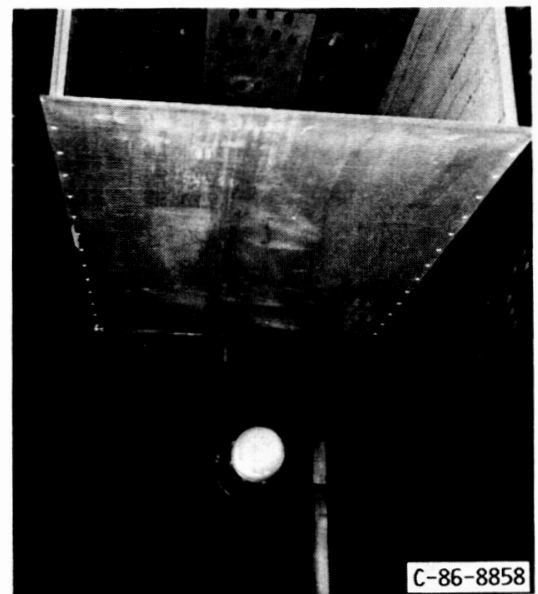

(b) PHOTOGRAPH.

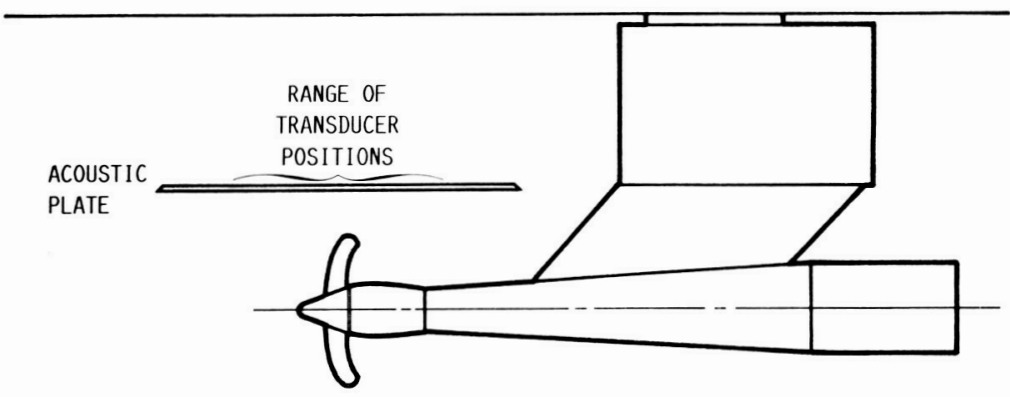

FIGURE 1. - SINGLE ROTATION PROPELLER INSTALLATION. 


\section{ORIGINAL PAGE IS \\ OF POOR QUALITY}

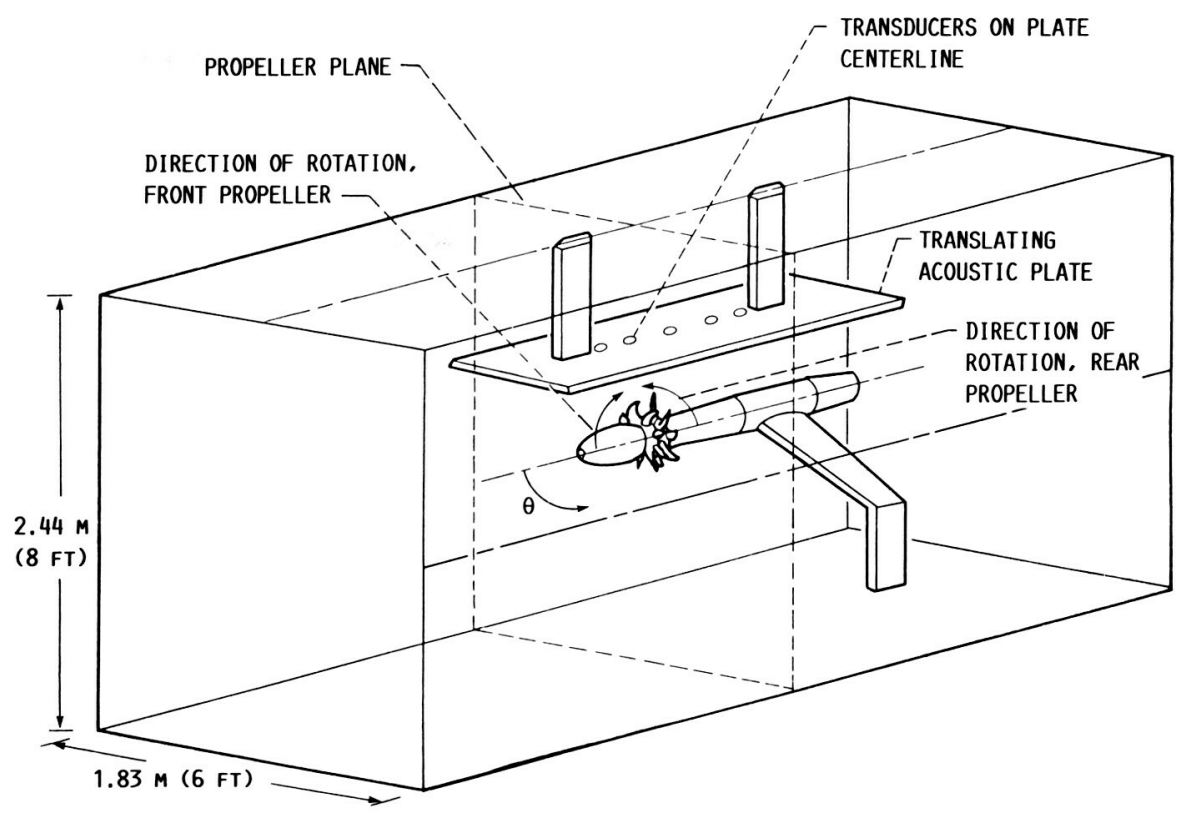

(a) PERSPECTIVE.

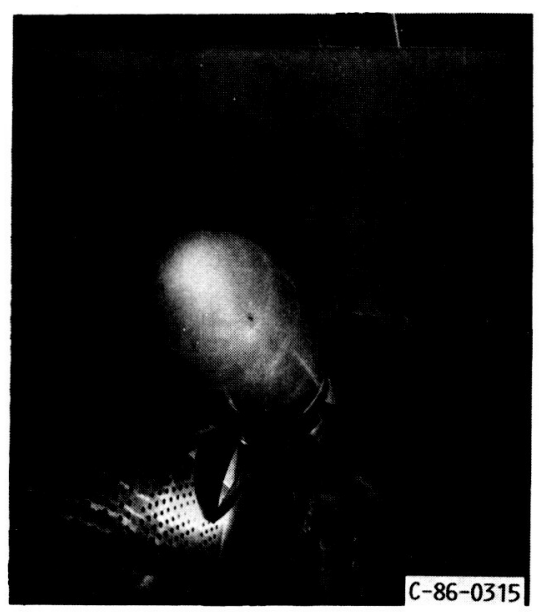

(b) PHOTOGRAPH.

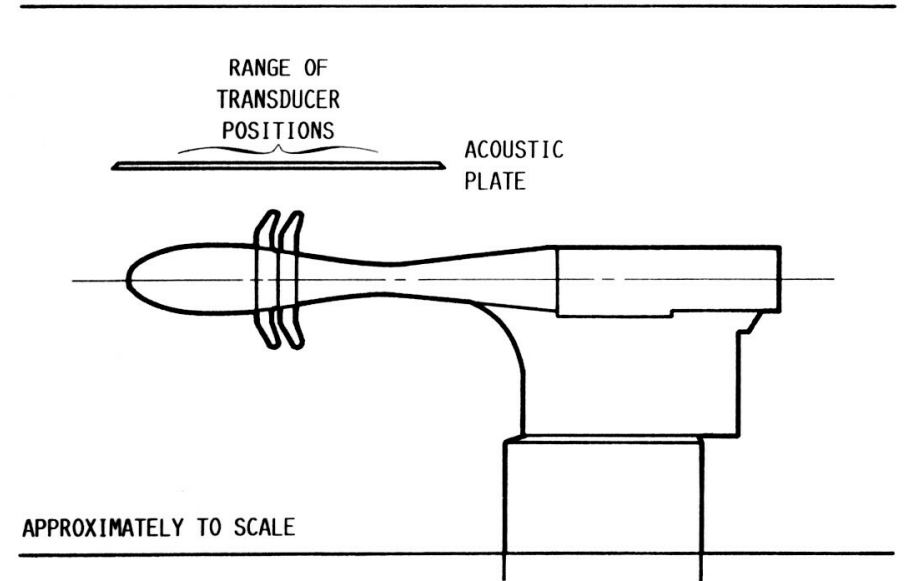

(c) SIDE VIEW.

FigURE 2. - COUNTERROTATION PROPELLER INSTALLATION. 
ORIGINAL PAGE IS

OF. POOR QUALITY

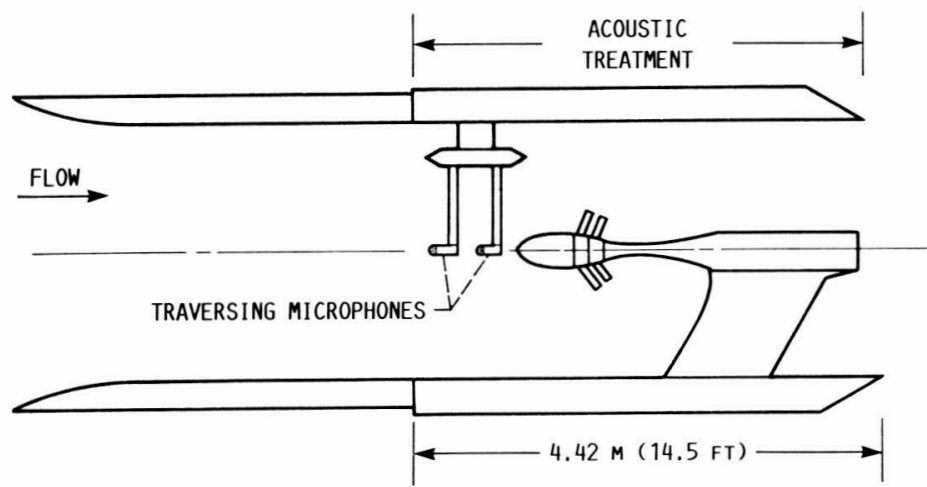

(a) SIDE VIEW.

FIGURE 3. - BOEING TRANSONIC WIND TUNNEL ACOUSTIC TEST SECTION.

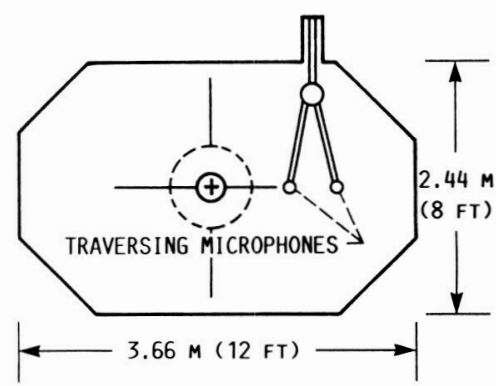

(b) VIEW UPSTREAM.

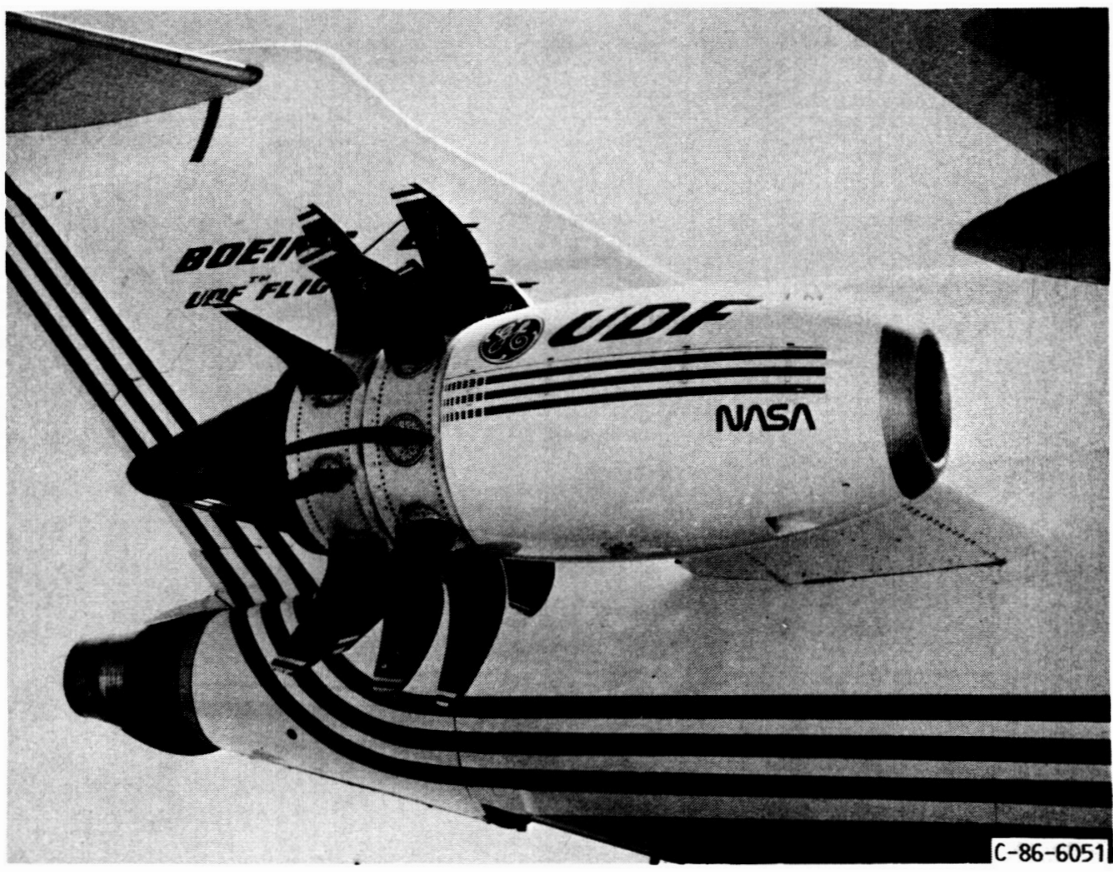

FIGURE 4. - PHOTOGRAPH OF THE COUNTERROTATION TURBOPROP ENGINE INSTALLED ON A BOEING 727 AIRCRAFT. 


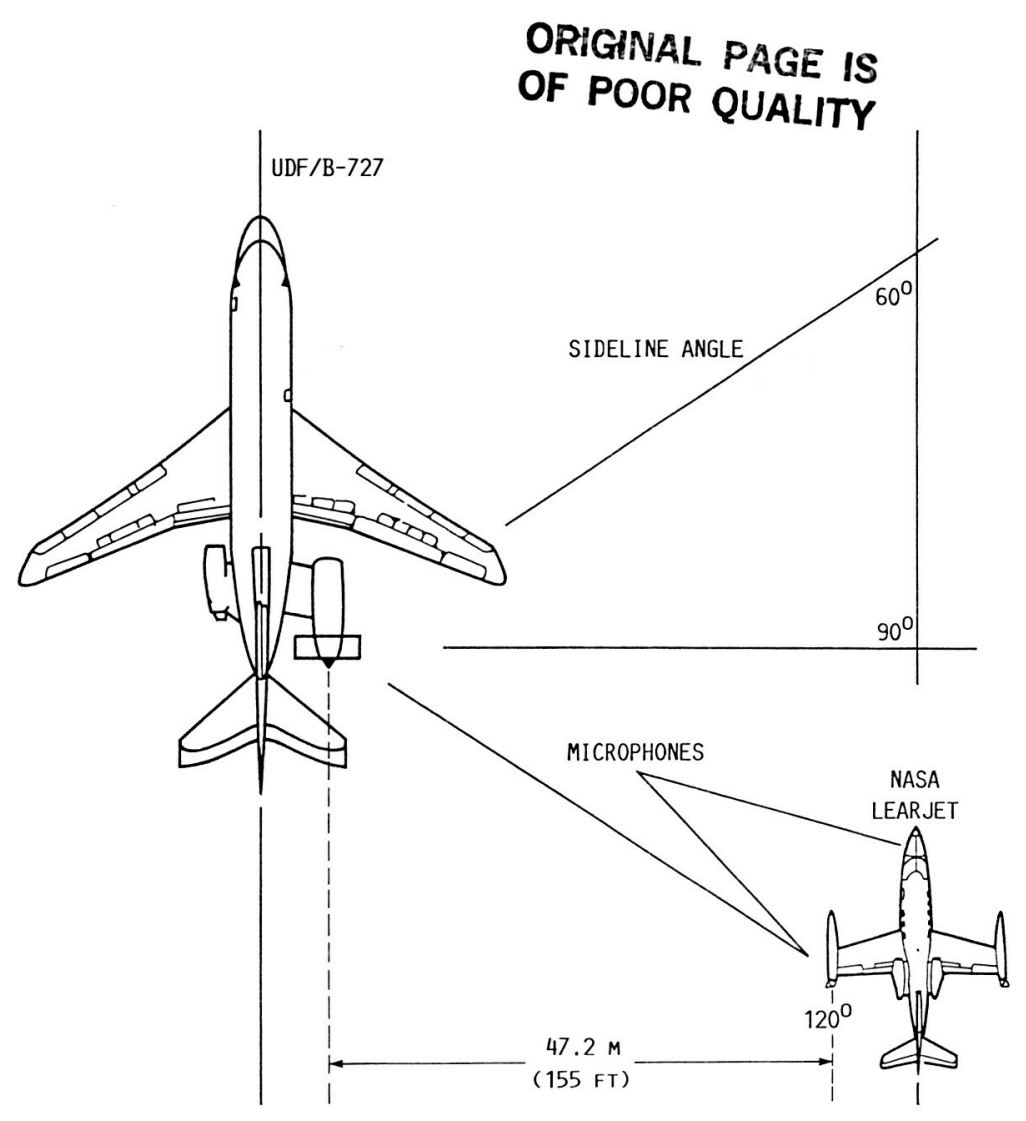

FIGURE 5. - SCHEMATIC OF LEARJET SIDELINE POSITIONING FOR ACOUSTIC DATA ACQUISITION.

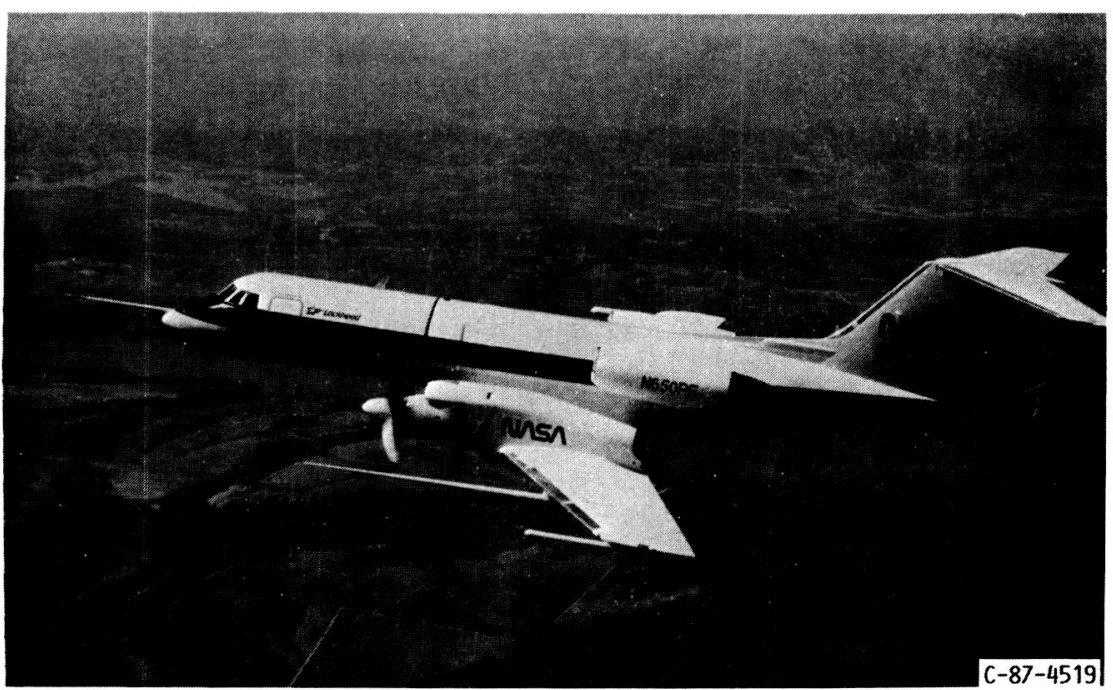

FIGURE 6. - LARGE-SCALE ADVANCED PROPFAN ON TEST BED AIRCRAFT. 

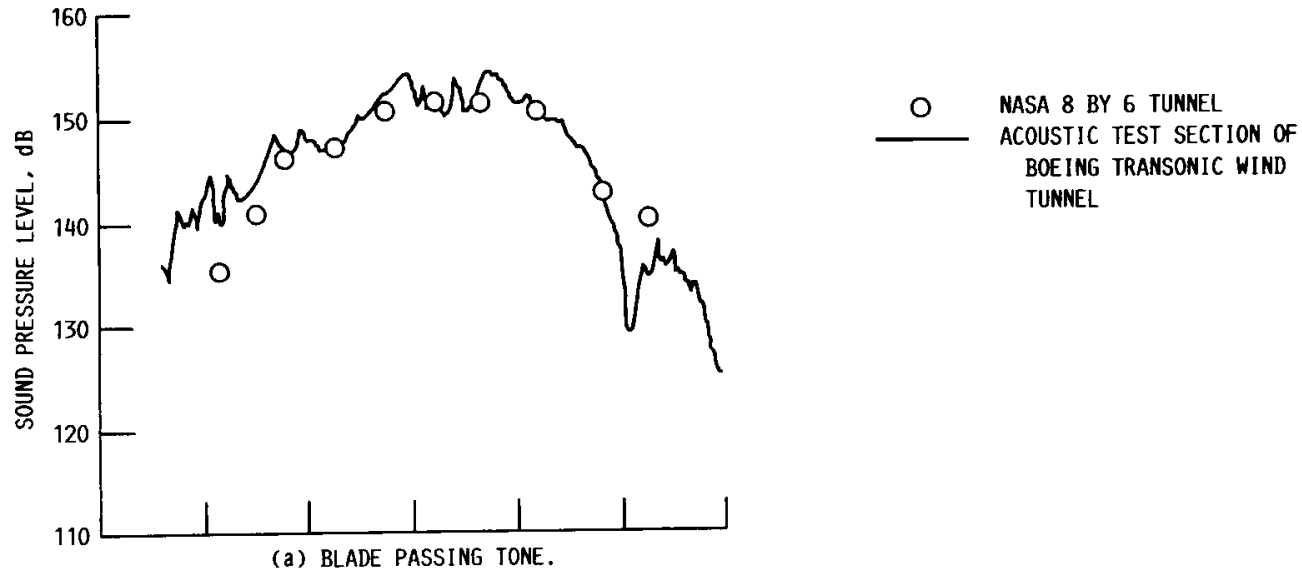

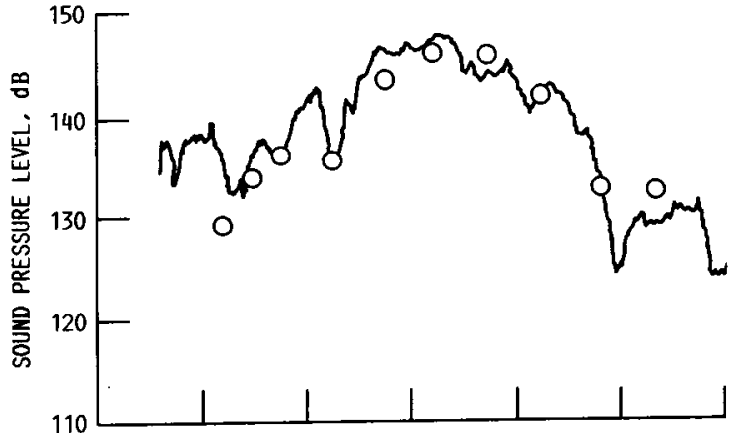

(b) TONE AT TWICE BLADE PASSING FREQUENCY.

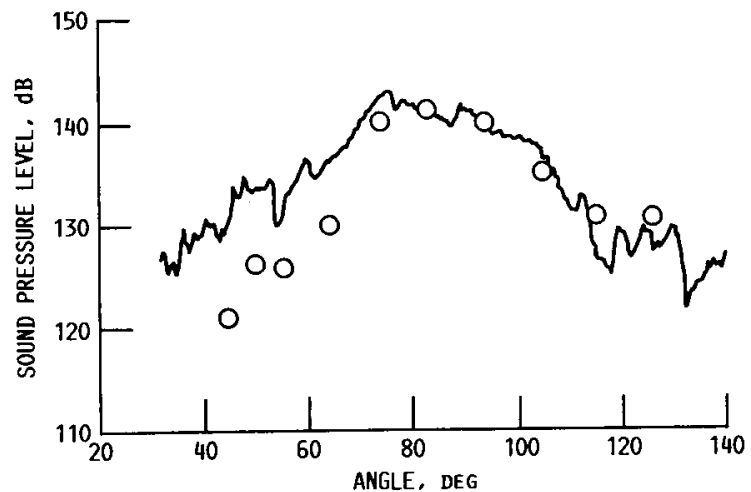

(c) TONE AT THREE TIMES BLADE PASSING FREQUENCY.

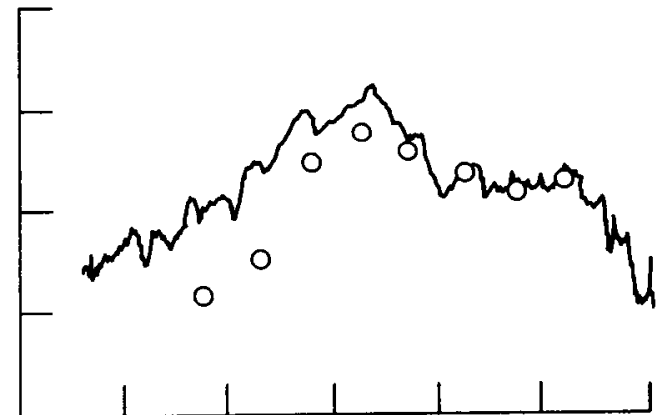

(d) TONE AT FOUR TIMES BLADE PASSING FREQUENCY.

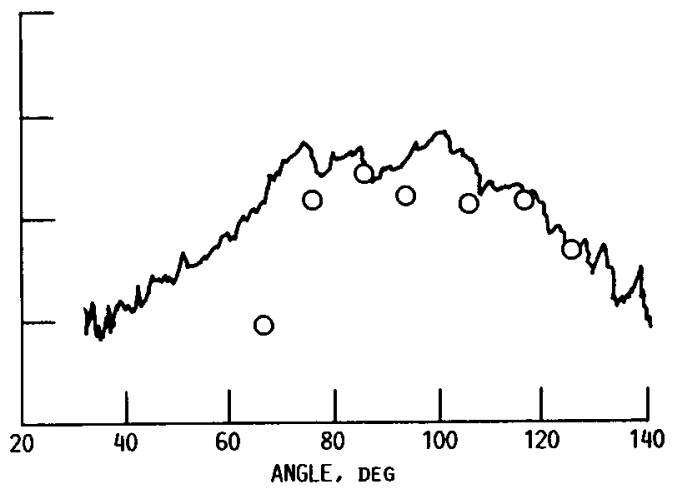

(e) TONE AT FIVE TIMES BLADE PASSING FREQUENCY.

FIGURE 7. - COMPARISON OF 8 BY 6 ACOUSTIC DATA AND BOEING ACOUSTIC DATA FOR F7-A7 COUNTERROTATION PROPELLER AT 100\% SPEED AT $M=0.72$ (DATA ADJUSTED TO BOEING CONDITIONS ON A 67-CM (2.2-FT) SIDELINE). 


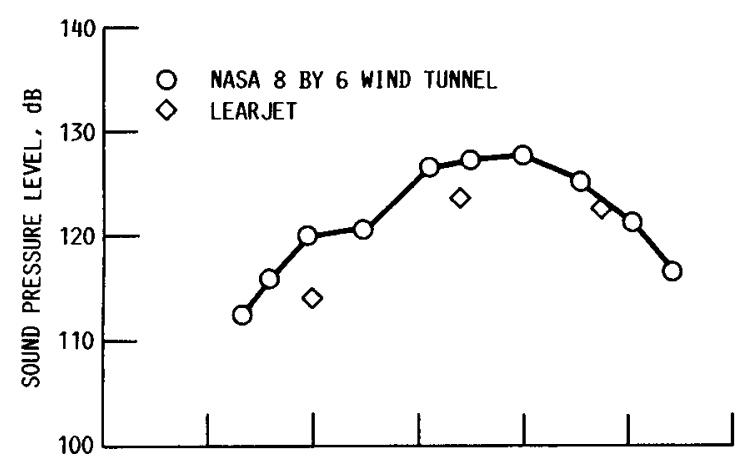

(a) BLADE PASSING TONE,

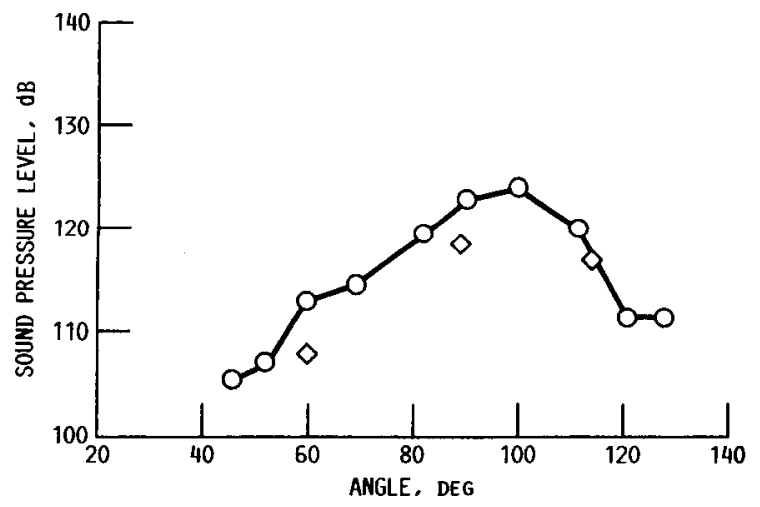

(b) TONE AT TWICE BLADE PASSING FREQUENCY.

FIGURE 8. - COMPARISON OF 8 BY 6 ACOUSTIC DATA AND LEARJET ACOUSTIC DATA FOR THE F7-A7 COUNTERROTATION PROPELLER (DATA ADJUSTED TO LEARJET CONDITIONS ON A 47.2-M (155-FT) SIDELINE).

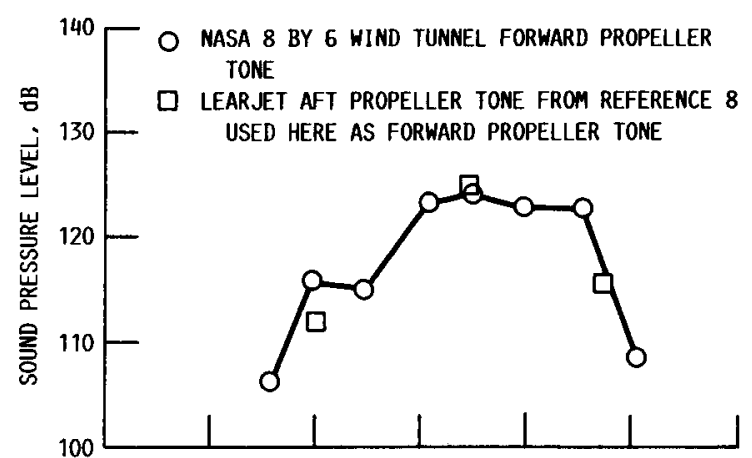

(a) BLADE PASSING TONE OF FORWARD PROPELLER.

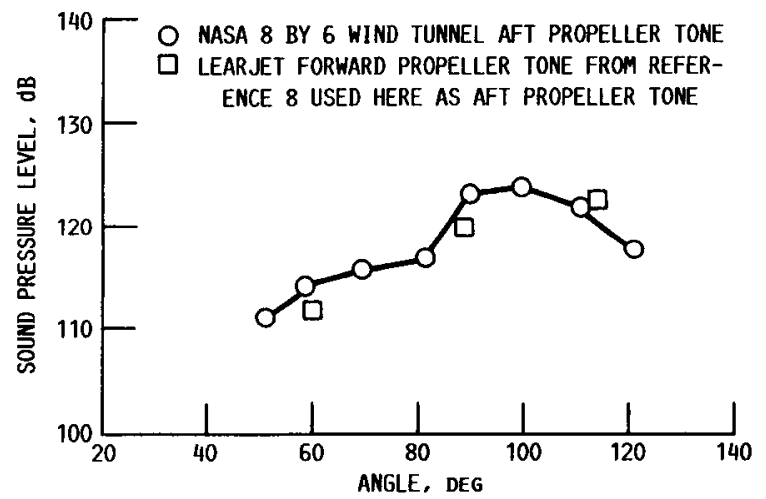

(b) BLADE PASSING TONE OF AFT PROPELLER.

FIGURE 9. - COMPARISON OF 8 BY 6 ACOUSTIC DATA AND LEARJET ACOUSTIC DATA FOR THE F7-A7 COUNTERROTATION PROPELLER (DATA ADJUSTED TO LEARJET CONDITIONS ON A 47.2-M (155-FT) SIDELINE). 


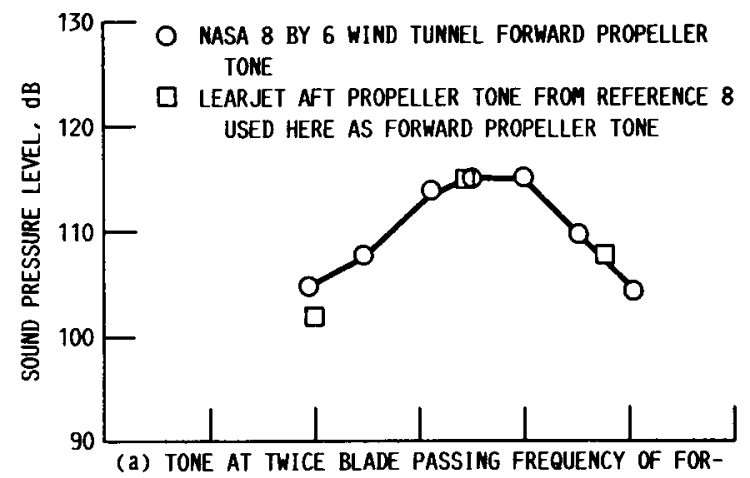
WARD PROPELLER.

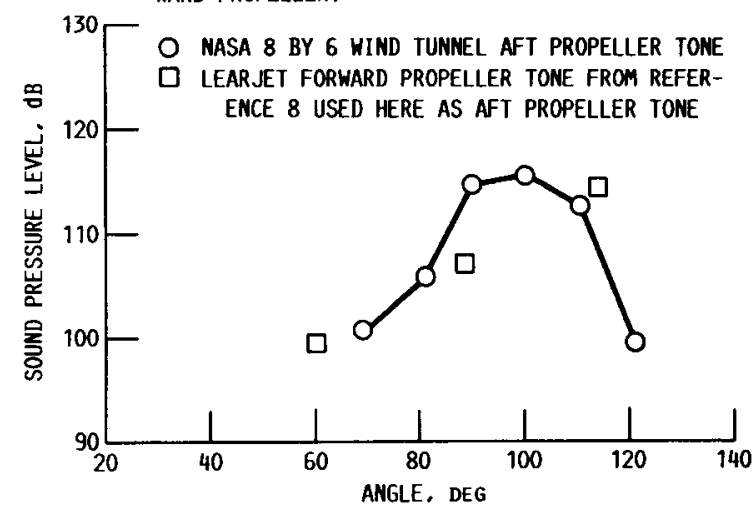

(b) TONE AT TWICE BLADE PASSING FREQUENCY OF AFT PROPELLER.

FIGURE 10. - COMPARISON OF 8 BY 6 ACOUSTIC DATA AND LEARJET ACOUSTIC DATA FOR THE F7-A7 COUNTERROTAIION PROPELLER (DATA ADJUSTED TO LEARJET CONDITIONS ON A 47.2-M (155-FT) SIDEL INE). 

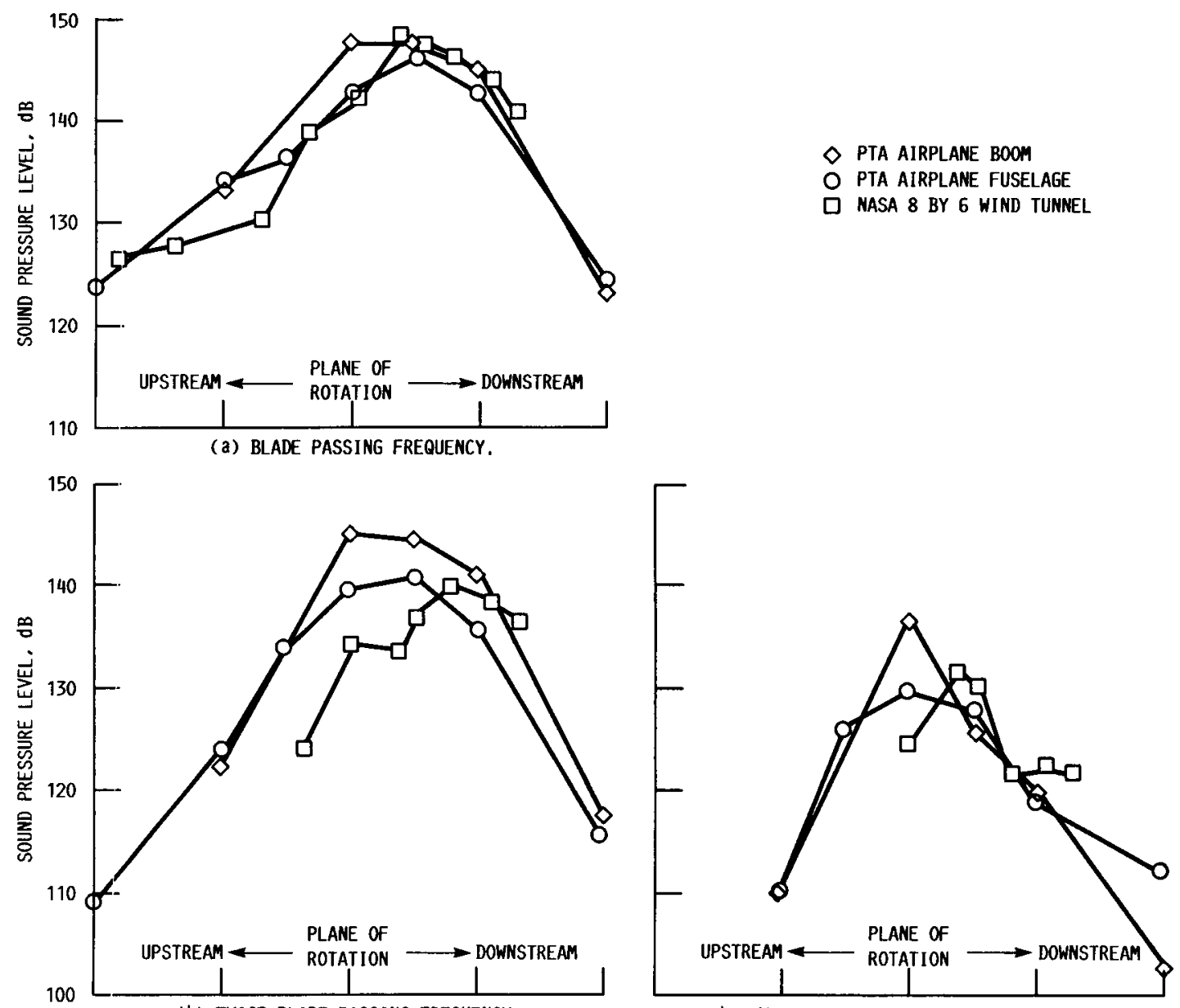

(d) FOUR TIMES BLADE PASSING FREQUENCY.
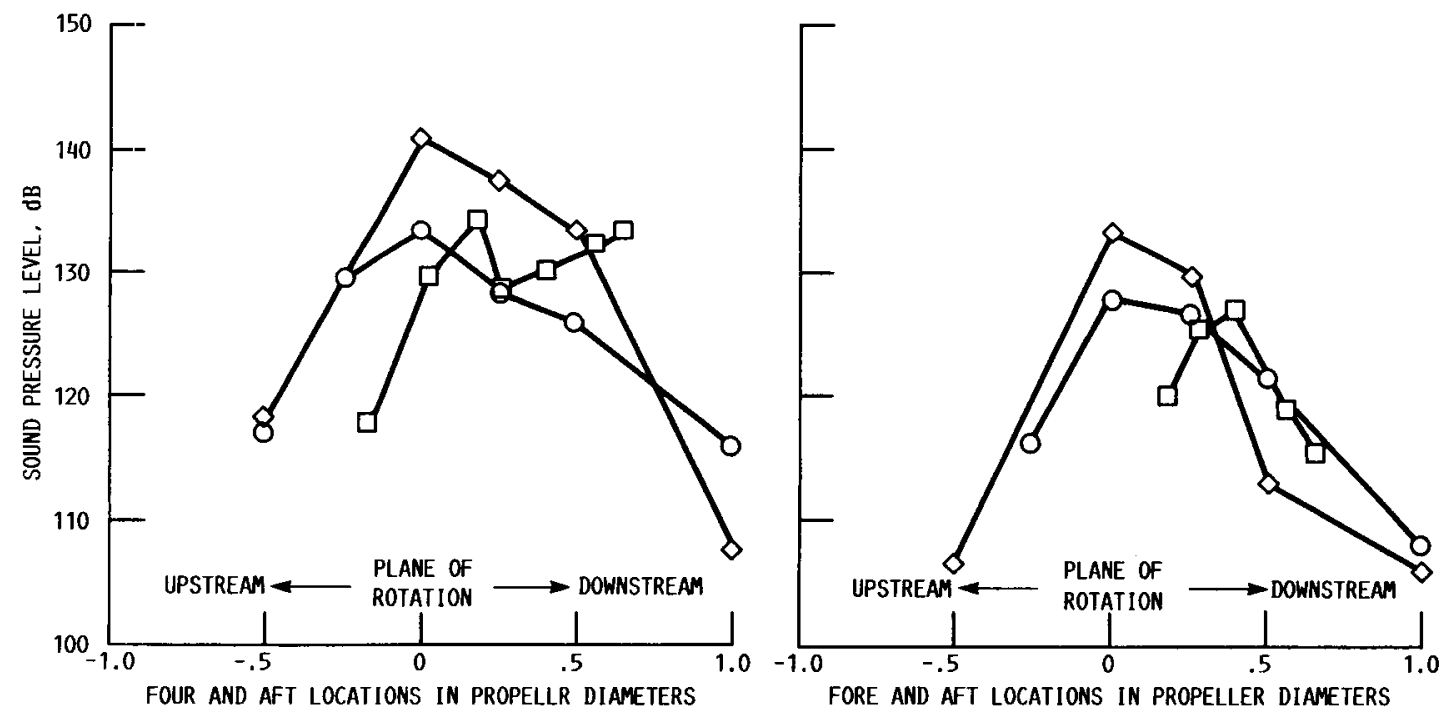

(c) THREE TIMES BLADE PASSING FREQUENCY.

(e) FIVE TIMES BLADE PASSING FREGUENCY.

FIGURE 11. - COMPARISON OF 8 BY 6 ACOUSTIC DATA WITH PTA DATA (DATA CORRECTED TO PTA FUSELAGE CONDITIONS ON A 3.05-M (10-FT) SIDELINE). 


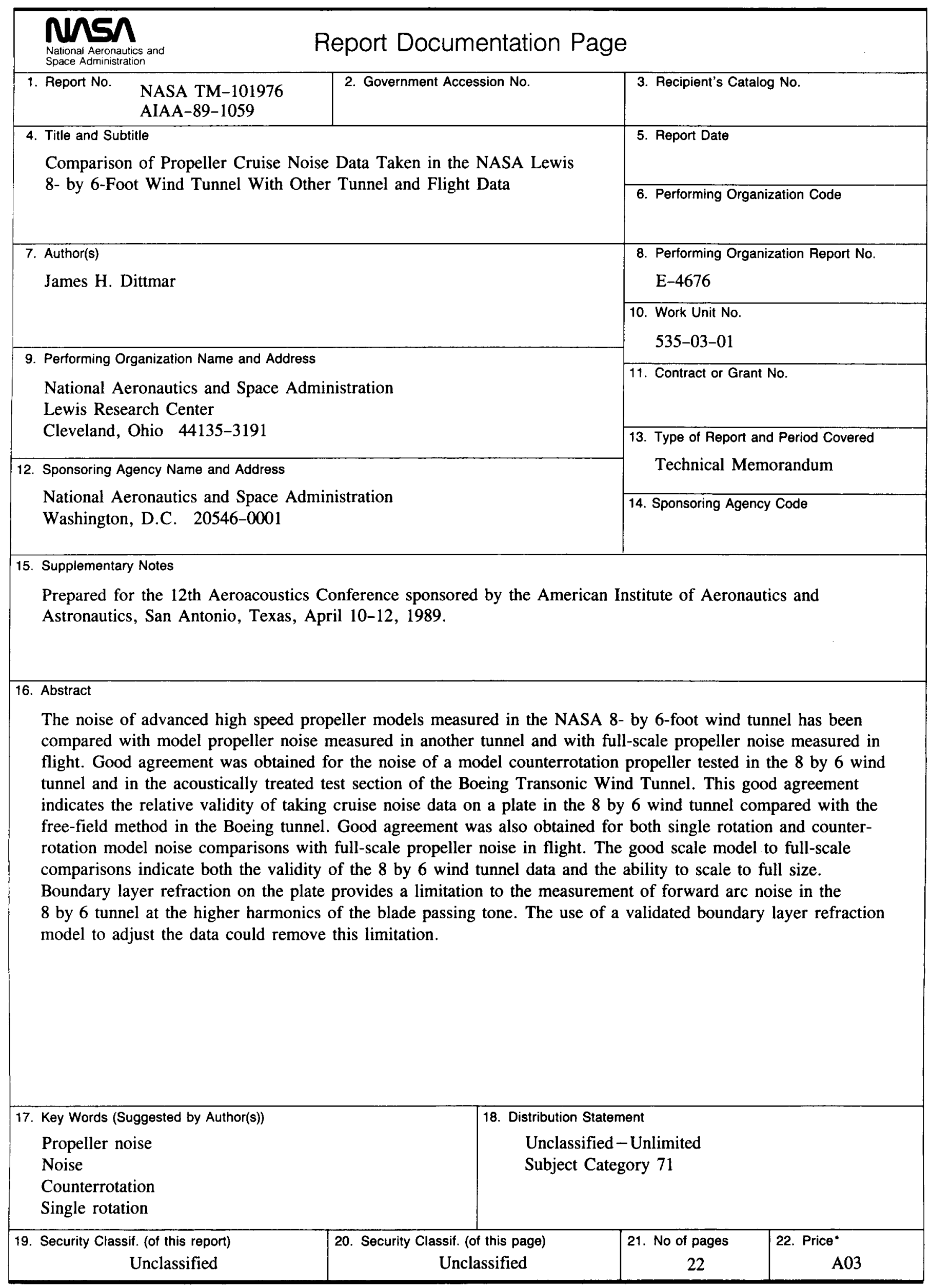

